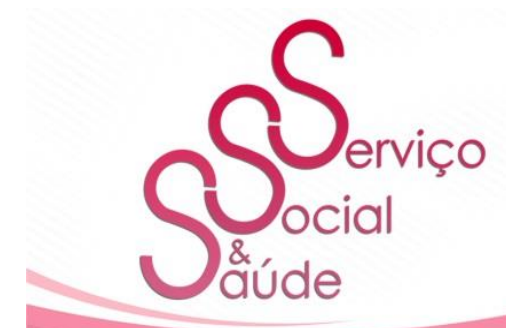

ISSN 2446-5992

(c) 10 (2)

10.20396/sss.v20i00.8665397

\title{
Serviço Social e defesa de direitos na Atenção Primária à Saúde
}

\author{
Social Work and defense rights in Primary Health Care
}

\section{Luciana Gonçalves Pereira de Paula ${ }^{1}$ \\ Karolina Adrienne Silva Oliveira ${ }^{2}$}

\begin{abstract}
RESUMO
O presente artigo propõe refletir acerca dos limites e das possibilidades que perpassam a garantia de direitos no trabalho dos assistentes sociais inseridos na Atenção Primária à Saúde, tendo por base a realidade do munícipio de Juiz de Fora - MG. O caminho metodológico utilizado compreendeu a realização de uma pesquisa empírica, de caráter qualitativo, obtendo dados coletados por meio de entrevistas semiestruturadas que foram posteriormente organizados, analisados e relacionados com o arcabouço teórico pesquisado e estudado. A partir da reflexão sobre as respostas apresentadas, em vários momentos, surgem características do capitalismo contemporâneo, perpassado pelo ideário neoliberal, o qual estimula a expropriação de direitos, a atrofia do Estado e das políticas sociais. No Entanto, embora os assistentes sociais encontrem limites que rebatem em sua autonomia profissional é possível estabelecer estratégias - profissionais e políticas - pautadas na perspectiva da garantia de direitos dos usuários do SUS.
\end{abstract}

Palavras-chave: Saúde. Atenção Primária. Trabalho. Assistente Social. Direitos.

\section{ABSTRACT}

This article proposes to reflect on the limits and possibilities that permeate the guarantee of rights in the work of social workers inserted in Primary Health Care, based on the reality of the Municipality of Juiz de Fora - MG. The methodological path used included an empirical research, of a qualitative

\footnotetext{
${ }^{1}$ Assistente Social pela Universidade Federal de Juiz de Fora (UFJF). Doutora em Serviço Social pelo Programa de Pós-Graduação em Serviço Social da Universidade Federal do Rio de Janeiro. Professora adjunta na Faculdade de Serviço Social da UFJF. Telefone: 553299955 8445. E-mail: lugppaula@gmail.com ${ }^{2}$ Assistente Social pela Universidade Federal de Juiz de Fora. Especialista em Saúde da Família pelo Programa de Residência Multiprofissional, Hospital Universitário/UFJF. Analista Social do Programa Central de Acompanhamento de Alternativas Penais (CEAPA). E-mail: karolasoliveira@ hotmail.com
} 


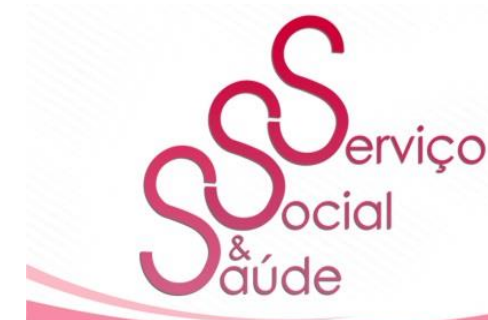

ISSN 2446-5992

(c) 10 (2)

10.20396/sss.v20i00.8665397

nature, obtaining data collected through semi-structured interviews that were later organized, analyzed and related to the theoretical framework researched and studied. From the reflection on the answers presented, at various moments, there are characteristics of contemporary capitalism, permeated by the neoliberal ideology, which stimulates the expropriation of rights, the atrophy of the state and social policies. However, although social workers find limits that hinder their professional autonomy, it is possible to establish strategies - professional and political - based on the perspective of guaranteeing the rights of SUS users.

KEYWORDS: Health. Primary Attention. Work. Social Worker. Rights.

\section{INTRODUÇÃO}

$\boldsymbol{O}$ presente artigo tem por objetivo refletir sobre os limites e as possibilidades que atravessam a defesa de direitos no trabalho profissional dos assistentes sociais, inseridos no campo da política de saúde, especialmente na atenção primária.

A maneira como a política de saúde se desenvolveu no Brasil, com a consolidação do Sistema Único de Saúde (SUS), com a incorporação do conceito ampliado de saúde, com a consideração da determinação social no processo saúde-doença, legitimou ainda mais a inserção dos assistentes sociais nessa política, em diferentes níveis de atenção e em diversas esferas de atuação.

Na Atenção Primária - entendida como o "primeiro ponto de atenção e principal porta de entrada do sistema, constituída de equipe multidisciplinar que cobre toda a população, integrando, coordenando o cuidado e atendendo às suas necessidades de saúde" (BRASIL, 2012, p. 25) - o assistente social vem sendo chamado para intervir nas mais diversas manifestações das expressões da questão social que atravessam as vidas dos usuários dos Serviços de Saúde.

No entanto, apesar dos assistentes sociais apresentarem, em sua maioria, um discurso que verbaliza um compromisso com o fortalecimento do SUS e com o projeto ético-político do Serviço Social, muitas vezes, essa intenção não se concretiza em ações que viabilizem essa 


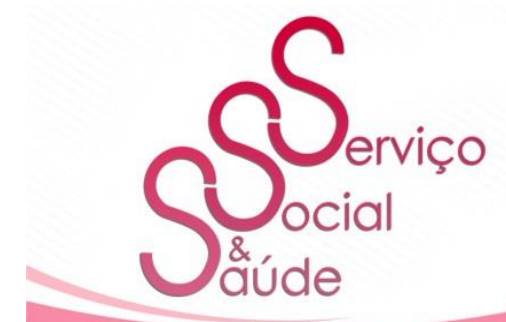

ISSN 2446-5992

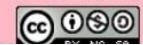

10.20396/sss.v20i00.8665397

perspectiva (VASCONCELOS, 2012).

Com o intuito de provocar o aprofundamento desse debate, o presente artigo traz alguns resultados de uma pesquisa empírica, de caráter qualitativo realizada com assistentes sociais inseridos na Atenção Primária à Saúde (APS) do município de Juiz de Fora/MG, nos anos de 2017 e 2018.

Entretanto, antes da exposição e análise dos dados, o artigo abordará um debate em torno da construção e da conceituação dos direitos sociais - onde se encontra o direito à saúde; as especificidades da realidade brasileira na construção desses direitos; e o desenvolvimento do trabalho profissional do assistente social na política de saúde, particularmente na APS.

\section{O QUE SÃO OS DIREITOS SOCIAIS?}

Os direitos sociais se constituíram, em nossa sociedade, enquanto produto histórico, resultado de um processo de lutas, respondendo, parcialmente, às aspirações, interesses e necessidades concretas de homens e mulheres. Tais aspirações, interesses e necessidades, que são reais e, portanto, materiais, são transpostos ao plano jurídico, configurando-se como direito, no âmbito do Estado.

Assim, o direito não é algo concedido "aos indivíduos de uma vez para sempre, não é algo que vem de cima para baixo, mas é resultado de uma luta permanente, travada quase sempre a partir de baixo, das classes subalternas, implicando um processo histórico de longa duração" (COUTINHO, 2008, p. 51).

Desse modo, os direitos não devem ser percebidos e considerados apenas como um elemento capturado pela burguesia e oferecido aos trabalhadores para legitimar sua dominação. Os direitos são, também e contraditoriamente, uma importante conquista da classe trabalhadora (COUTINHO, 2008).

A classe trabalhadora, ao se mobilizar e assumir seu papel organizativo no cenário 


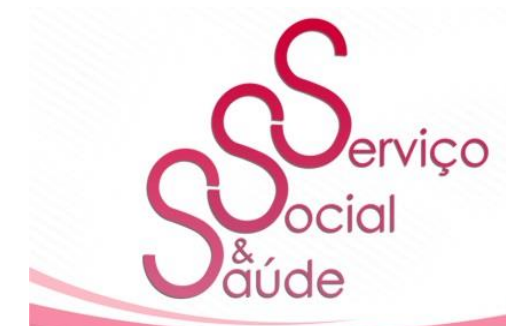

ISSN 2446-5992

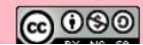

10.20396/sss.v20i00.8665397

político nos revela que, na sociedade capitalista, os direitos estarão sempre circunscritos aos limites dos interesses burgueses, e disponíveis apenas a uma parcela da população. Assim, "o homem universal não passa de uma abstração, vazia de significado no plano da realidade" (BUSSINGER, 1997, p. 30). Ou seja, a sociedade capitalista é dividida em classes sociais e o Estado, representando a razão da burguesia, pauta-se no "formalismo jurídico individualista (que) nos chama a todos de iguais, sem (nos) permitir ver as divisões de classe que nos estruturam" (MASCARO, 2015, p. 17).

Historicamente observamos que, em determinadas conjunturas, o capitalismo avança em seu desenvolvimento, contudo, em outros momentos, necessita responder às reivindicações da classe trabalhadora para assegurar sua legitimidade. Nesses momentos, configuram-se os direitos sociais, em maior ou menor escala, a depender da capacidade organizativa dos trabalhadores. Porém, esse processo ocorre sem colocar em xeque a estrutura e a lógica do capital, ou seja, perpetuando a exploração do trabalho e as desigualdades sociais.

Dessa maneira, verifica-se a contradição existente entre o desenvolvimento do capitalismo e a universalização de direitos, uma vez que a plena realização destes vai de encontro à lógica do capital. Os direitos apenas poderiam se estender a todos e assumir, de fato, uma condição de universalidade em uma sociedade que não fosse fraturada em classes sociais.

Assim, a "igualdade" garantida por lei, nas sociedades democráticas, não finda com as desigualdades que efetivamente regem a sociedade capitalista, pois estas só são superadas com a supressão desse sistema. "E isso conduz à conclusão inevitável de que, muito mais do que a emancipação política, o que a burguesia leva mesmo a sério, é a defesa dos seus interesses econômicos de classe" (TRINDADE, 2011, p. 81).

Com isso, percebemos que a luta por direitos deve se constituir como um meio e não como um fim. Ela se constitui como uma ferramenta importante para o processo de mobilização, organização e conscientização da classe trabalhadora, mas não é capaz de provocar a ruptura com a ordem do capital. Para a plena realização das necessidades humanas 


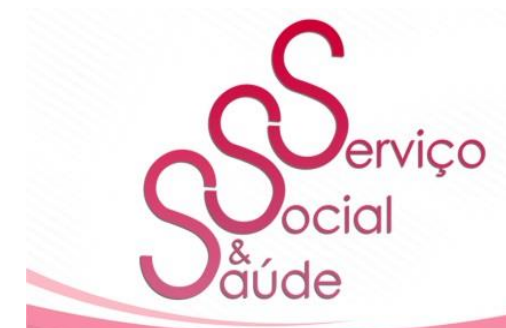

ISSN 2446-5992

(๑⿻)

10.20396/sss.v20i00.8665397

"é preciso acabar com a estrutura que gera o Estado e todo esse conjunto de normas" (MASCARO, 2015, p. 22).

Assim sendo, é fundamental lutar - política e ideologicamente - pela efetivação dos direitos na sociedade, pois "não há direito sem a sua realização" e, portanto, para que estes não passem de mera abstração é preciso a construção de uma democracia de massa com livre e pleno exercício da participação, isto é, “propor a ultrapassagem da mera emancipação política para uma emancipação humana" (TRINDADE, 2011, p. 82).

\section{A LUTA POR DIREITOS NA SOCIEDADE BRASILEIRA}

Considerando o processo de luta por direitos, no Brasil, é de suma importância destacar a Constituição Federal de 1988 (CF/88), que representa uma conquista dos trabalhadores e dos movimentos sociais progressistas. A Carta Magna reconhece uma enorme gama de direitos - sociais e individuais - destinados à população como um todo e representa o processo de democratização do nosso país. A referida carta considera a saúde como "direito de todos e dever do Estado, garantido mediante políticas sociais e econômicas que visem à redução do risco de doença e de outros agravos e ao acesso universal e igualitário às ações e serviços para sua promoção, proteção e recuperação" (BRASIL, 1988, p. 118).

No entanto, por mais que a $\mathrm{CF} / 88$ tenha reconhecido, formalmente, uma série de garantias e direitos, dentre eles a saúde, pouco se avançou na efetivação destes frente a um contexto de desigualdades sociais. Assim, apesar de garantidos legalmente, os direitos não têm assegurada sua automática efetivação na realidade social e a burguesia, pautada no ideário neoliberal, os desconsideram enquanto fruto da luta de classe, encobrindo os antagonismos e reforçando a negação destes.

No que tange a progressiva destituição de direitos, na atual conjuntura, Fagnani (2017) afirma que o período de 2016-2018 pode representar o término do breve ciclo da construção da cidadania social no Brasil (1988-2015). Sendo executado através de seis atos principais: 


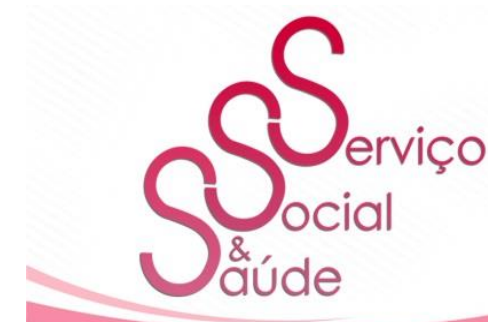

ISSN 2446-5992

(c) 10 (2)

10.20396/sss.v20i00.8665397

ampliação da desvinculação constitucional de recursos das políticas sociais; o "Novo Regime Fiscal" (PEC 55); o fim da vinculação de recursos para a área social (educação e saúde); reforma da Previdência Social; reforma Tributária; retrocesso nos direitos trabalhistas e sindicais. Portanto, "sob o rótulo de reforma(s) o que vem sendo conduzida(s) pelo grande capital é um gigantesco processo de contrarreforma(s), destinado à supressão ou redução de direitos e garantias sociais" (NETTO; BRAZ, 2006, p. 227).

Como indica Netto (1996), ocorre uma diminuição da esfera estatal nas funções relacionadas à satisfação de direitos sociais, sendo o Estado mínimo para a classe trabalhadora e máximo para o capital, uma vez que a economia capitalista não pode funcionar sem a intervenção estatal.

Essa é uma clara prova de que os direitos sociais não interessam à burguesia: em algumas conjunturas, ela pode até tolerá-los e tentar usá-los a seu favor, mas se empenha em limitá-los e suprimi-los sempre que, nos momentos de recessão (que são inevitáveis no capitalismo), tais direitos se revelam contrários à lógica capitalista da ampliação máxima da taxa de lucro (COUTINHO, 2008, p. 66-67).

Dessa forma, o Estado oferece políticas sociais cada vez mais restritas, seletivas e focalizadas, somente para atender às necessidades básicas de reprodução da classe trabalhadora, obstaculizando a organização popular para a conquista de direitos, como por exemplo, implementando programas residuais sem referência a direitos, concedidos como benesse, apenas para complementar o que não se obteve via mercado ou sociedade civil. Prevalecendo, assim, o discurso da filantropia, do assistencialismo e do clientelismo, transformando em favor o que é direito, ou seja, uma perversa regressão dos direitos sociais.

Portanto, para que os direitos sociais possam se efetivar, em uma perspectiva de conquista dos trabalhadores, é preciso que haja uma conjuntura favorável para esse processo. Porém, esta luta, quase sempre, esbarra em mecanismos favoráveis aos interesses dominantes, que limitam o caráter de universalidade dos direitos.

Neste sentido, avançar na afirmação destes não é tarefa fácil, visto que o discurso reproduzido sobre tais direitos é funcional e adequado ao padrão de reprodução social vigente. 


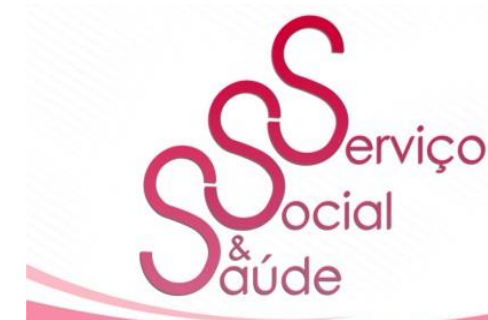

ISSN 2446-5992

(c) 10 (2)

10.20396/sss.v20i00.8665397

E os direitos somente poderão se estender a todos em uma sociedade que não a de classes.

Sua conquista deve considerar o terreno da soberania popular, possível de efetivar-se na realização do Estado democrático moderno, como um espaço contraditório de lutas de classe e interesses adversos que podem, e devem, intermediar a construção de uma sociedade em que os direitos, a liberdade e a igualdade se efetuem como condições básicas e imprescindíveis à realização do ideal de emancipação humana (SILVA, 2012, p. 41).

Desse modo, a defesa das políticas sociais é fundamental, principalmente no contexto da realidade brasileira de imensas desigualdades e concentração de renda. Porém, não é responsabilidade dessas políticas realizar o enfrentamento dessa realidade, muito menos a sua superação. "Nunca é demais afirmar que defender no capitalismo as políticas sociais é uma estratégia, mas não um fim em si mesmo. Tais desigualdades só se podem superar com a supressão do capitalismo" (MATOS, 2013, p. 65).

\section{AS POLÍTICAS SOCIAIS E O SERVIÇO SOCIAL - ENFOQUE NO CAMPO DA SAÚDE}

Conforme apontam Iamamoto e Carvalho (2008) existe uma ligação estrutural entre a constituição das políticas sociais e o surgimento do Serviço Social na divisão social e técnica do trabalho, estando o profissional inserido no processo de reprodução das relações sociais da sociedade capitalista. Dessa forma, a intervenção profissional se dá sobre as diversas manifestações das expressões da questão social, no âmbito das políticas sociais. "É nesta tensão entre produção da desigualdade e produção da rebeldia e da resistência, que trabalham os assistentes sociais, situados nesse terreno, movidos por interesses sociais distintos" (IAMAMOTO, 2008a, p. 28).

A Constituição de 1988 e a Lei Orgânica da Saúde de 1990 incorporaram os ideais da Reforma Sanitária compreendendo a saúde como um direito de todos e dever do Estado, devendo ser garantido mediante políticas sociais e econômicas, visando à promoção da saúde.

Além disso, a partir da $8^{\text {a }}$ Conferência Nacional de Saúde, passou-se a ser adotado um 


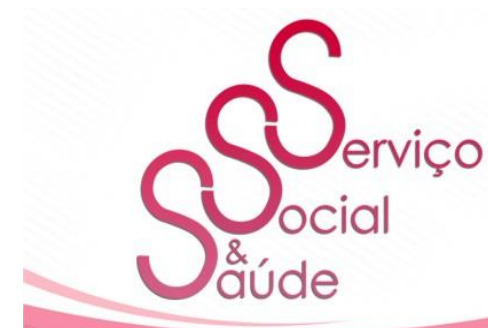

ISSN 2446-5992

(c) 10 (2)

10.20396/sss.v20i00.8665397

novo e mais ampliado conceito de saúde, que considera os determinantes sociais do processo saúde-doença.

Portanto, conforme aponta Mioto e Nogueira (2008) a partir da implantação do SUS tem-se a adoção do paradigma da saúde como resultante das condições de alimentação, educação, renda, trabalho, transporte, entre outros, ocorrendo uma reconfiguração dos discursos e das práticas profissionais no campo da assistência à saúde.

Nesse sentido,

Reafirma-se que o Serviço Social tem um conhecimento acumulado que o habilita a concretizar as ações demandadas na perspectiva da promoção à saúde, desde que se inscrevam de forma sistematizada e articulada aos marcos teóricos em curso. Nesse contexto, a ação profissional é entendida pela ótica da totalidade (MIOTO; NOGUEIRA, 2008, p. 280-281).

A Resolução do CFESS no 383 de 1999 caracteriza o assistente social como profissional da saúde, assim como a Resolução no 218/1997 do Conselho Nacional de Saúde já o reconhecia. E o Serviço Social, hoje, possui atuação reconhecida em todos os níveis de atenção e equipamentos dos serviços de saúde - compreendendo que esses espaços constituem a efetivação da política de saúde, tendo o assistente social esse âmbito como seu principal espaço sócio-ocupacional.

Dentro da estrutura organizativa do SUS, a Atenção Primária à Saúde (APS), como aponta Mendes (2010), se caracteriza como uma estratégia ${ }^{3}$ dentro dos serviços de saúde, reorganizando, reordenando e coordenando as ações. Ela permite ofertar uma atenção contínua e integral à população, visando o atendimento de suas necessidades, sendo parte de um sistema integrado de serviços de saúde.

Conforme aponta Castro (2009), desde 1990, com os processos de descentralização dos serviços, os municípios passaram a ter a atribuição de gerir a atenção básica ${ }^{4}$, as ações de

\footnotetext{
${ }^{3}$ Ressalta-se que Mendes (2010) propõe essa organização através da implantação de redes de atenção à saúde que se constituem com três elementos: população, estrutura operacional e modelo de atenção à saúde.

${ }^{4}$ Que de acordo com a Política Nacional de Atenção Básica (2012) se caracteriza pelo conjunto de ações de saúde, tanto individual quanto coletivo, objetivando a promoção, a prevenção, o diagnóstico, o tratamento, a Serv. Soc. \& Saúde Campinas, SP v. 20 \begin{tabular}{l|l|l}
$1-22$ & e021004 & 2021
\end{tabular} e-ISSN 2446-5992
} 


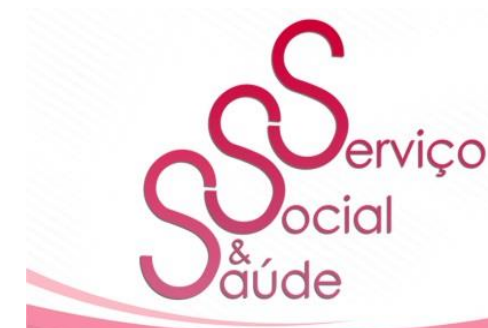

ISSN 2446-5992

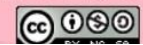

10.20396/sss.v20i00.8665397

vigilância, a articulação com o estado na regionalização da rede e a implantação das políticas do governo federal. Passara, assim, a ofertar os serviços da atenção primária à saúde, através das Unidades Básicas de Saúde (UBS).

Ainda de acordo com Castro (2009), objetivando garantir resolutividade, a atenção básica deve conter uma determinada infraestrutura e recursos humanos (equipe multiprofissional) além de garantir uma assistência básica, de forma integral e contínua; implementar a Política Nacional de Humanização (como por exemplo, com a realização do acolhimento); realizar planejamento e avaliação das ações de saúde; e fortalecer a gestão local e o controle social.

Nessa esfera da atenção primária à saúde, desenvolvida nas UBS, a partir de 1994, teve início a adoção do Programa de Saúde da Família ${ }^{5}$, apontado pelo Ministério da Saúde como principal estratégia de reorganização da atenção básica, em consonância com os preceitos dos SUS - e justamente por isso, passou a ser denominado, posteriormente, como Estratégia em Saúde da Família (ESF).

Ainda segundo o Ministério da Saúde um dos itens necessários à Estratégia em Saúde da Família é a existência de uma equipe multiprofissional mínima ${ }^{6}$ (equipe Saúde da Família) que pode ser acrescida com outras categorias profissionais, como o assistente social.

A inserção do assistente social no campo da saúde, por sua vez, possui especificidades/particularidades que necessitam serem descobertas, pois, conforme aponta Castro (2009), se trata de um espaço que possui centralidade no trabalho vivo e produz ações que objetivam o cuidado dos usuários. Especificidades ampliadas na atenção primária, haja

\footnotetext{
reabilitação, a redução de danos e a manutenção da saúde. Tais ações devem ser desenvolvidas através de práticas gerenciais e sanitárias, democráticas e participativas, coma a realização do trabalho em equipe para populações de territórios definidos. A atenção básica se orienta pelos princípios da universalidade, acessibilidade e coordenação do cuidado, vínculo e continuidade, integralidade, responsabilização, humanização, equidade e participação social.

${ }^{5}$ Inicialmente nomeada Programa Saúde da Família (PSF) e que muda para Estratégia Saúde da Família(ESF), em 1996.

6 "Composta por médico generalista ou especialista em Saúde da Família ou médico de Família e Comunidade, enfermeiro generalista ou especialista em Saúde da Família, auxiliar ou técnico de enfermagem e agentes comunitários de saúde" (BRASIL, 2012, p. 55).

\begin{tabular}{|l|l|l|l|l|l|l|} 
Serv. Soc. \& Saúde & Campinas, SP & v. 20 & $1-22$ & e021004 & 2021 & e-ISSN 2446-5992
\end{tabular}
}




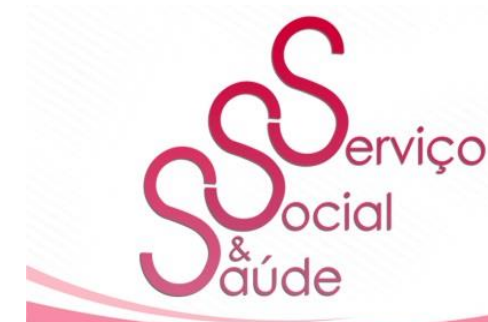

ISSN 2446-5992

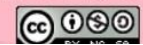

10.20396/sss.v20i00.8665397

vista que é onde ocorre, ou pelo menos deveria ocorrer, a entrada desses usuários nos serviços de saúde, o que proporciona um contato privilegiado com esses sujeitos e com sua rotina de vida.

Portanto, conforme aponta Matos (2013), torna-se imprescindível apreender os determinantes da política de saúde e seus rebatimentos no trabalho desenvolvido na instituição e na vida dos usuários. Pois, o trabalhador assistente social é chamado para atuar nas mais diversas expressões da questão social, que perpassam o processo saúde-doença. Além, de também ser chamado para atuar nas contradições e/ou omissões geradas pela não efetivação de direitos.

Então, o profissional necessita continuar lutando pela efetiva implementação do projeto da reforma sanitária e sua articulação com o projeto ético-político da profissão, já que ambos apresentam uma relação direta:

Há uma relação entre o projeto ético-político e o de reforma sanitária, principalmente, nos seus grandes eixos: principais aportes e referências teóricas, formação profissional e princípios. Os dois projetos são construídos no processo de redemocratização da sociedade brasileira e se consolidam na década de 1980. As demandas democráticas e populares, a mobilização e organização dos trabalhadores urbanos e rurais colocam na agenda política brasileira a exigência de transformações políticas e sociais e a necessidade de articulação dos projetos profissionais aos projetos societários que são propostos para o conjunto da sociedade (CFESS, 2010, p. 26).

Iamamoto (2008a, p. 20) aponta que, atualmente, o assistente social possui o desafio de "desenvolver sua capacidade de decifrar a realidade e construir propostas de trabalho criativas e capazes de preservar e efetivar direitos, a partir de demandas emergentes no cotidiano". Portanto, cabe ao profissional ser propositivo e contribuir para viabilização, expansão do direito social à saúde, juntamente com outros trabalhadores, com os movimentos sociais que defendem a Atenção Primária, o SUS. Pois, "sabem os assistentes sociais que o êxito do seu trabalho depende da articulação de uma rede de serviços e de profissionais, dentro e fora do seu local de trabalho" (MATOS, 2013, p. 64). 


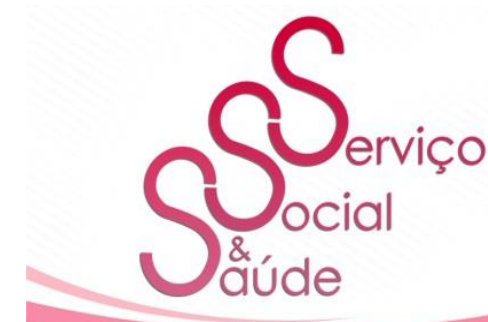

ISSN 2446-5992

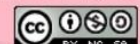

10.20396/sss.v20i00.8665397

Portanto, o profissional necessita compreender a realidade institucional da Unidade de Saúde que está inserido, analisar os limites (tanto das políticas e serviços de saúde quanto da profissão) para construir estratégias/possibilidades, inclusive coletivas, e assim garantir a escuta qualificada dos usuários, fortalecer espaços de participação social, desenvolver ações interdisciplinares e intersetoriais, realizar trabalhos educativos, informativos, visando a democratização da saúde, a prevenção, a promoção, a resolutividade, ou seja, garantindo os direitos da política de saúde.

Porém, como supracitado defender as políticas sociais deve ser uma estratégia, mas não um fim em si mesmo, pois estas não superam as desigualdades inerentes ao capitalismo. Assim, para se garantir transformações estruturais nas Unidades de Saúde e na política de saúde como um todo é necessário um "amplo movimento de massas que questione a cultura política da crise gestada pelo grande capital e que lute pela ampliação da democracia nas esferas da economia, da política e da cultura" (CFESS, 2010, p. 23).

\section{A REALIDADE DO SERVIÇO SOCIAL EM UBSS DO MUNICÍPIO DE JUIZ DE}

\section{FORA/MG}

Em Juiz de Fora/MG, segundo dados da Secretaria de Saúde do município, a rede de serviços da APS está organizada em sessenta e três Unidades Básicas de Saúde (UBS) ${ }^{7}$. Sendo que destas, apenas dezoito possuem assistente social.

Em nossa pesquisa, que foi submetida e aprovada ${ }^{8}$ pelo Comitê de Ética em pesquisa Humana (Universidade Federal de Juiz de Fora - MG), o universo de assistentes sociais a ser entrevistado foi constituído pelo grupo de profissionais que estava trabalhando em UBS no segundo semestre de 2017. Levando-se em conta os seguintes critérios de exclusão:

\footnotetext{
${ }^{7}$ Em Juiz de Fora, os antigos "postos de saúde" que passaram a se chamar Unidades de Atenção Primária à Saúde (UAPS), seguindo a tendência nacional, desde 2010, voltaram à denominação Unidade Básica de Saúde (UBS) por meio de um decreto municipal de 08/08/2017. A justificativa foi evitar a confusão entre UAPS e UPAs (Unidades de Pronto Atendimento), identificada como muito comum entre os/as usuários/as.

${ }^{8} \mathrm{O}$ projeto foi submetido à apreciação e aprovado pelo Comitê de Ética em Pesquisa da Universidade Federal de Juiz de Fora com CAAE de cadastramento $\mathrm{n}^{\circ}$ 67190317.0.0000.5147, tendo recebido parecer favorável em 22.05.2017. 


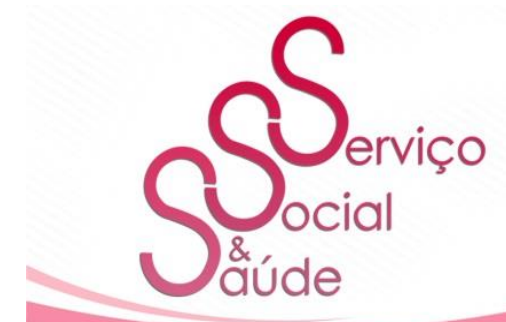

ISSN 2446-5992

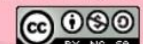

10.20396/sss.v20i00.8665397

profissionais que no período da realização das entrevistas estavam, por algum motivo, afastados do trabalho (tais como férias, licença maternidade, auxílio-doença, aposentadoria); profissionais inseridos em UBS localizadas na Zona Rural; e profissionais que iniciaram as atividades a menos de seis meses.

Portanto, diante dos critérios de exclusão o número de sujeitos participantes da pesquisa reduziu de dezoito para onze. Porém, após contato inicial e outras inúmeras tentativas, apenas cinco profissionais concordaram em participar da pesquisa. Diante de tal intercorrência, o número de entrevistadas - cinco - passou a representar a amostra do estudo.

Assim, após a aprovação do Comitê de Ética em Pesquisa, a análise dos dados, coletados nas entrevistas, inicia com as perguntas referentes ao perfil dos profissionais e a sua formação e, na sequência, as questões relativas ao trabalho do assistente social, reproduzindo a lógica que presidiu o roteiro utilizado nas entrevistas.

\section{PERFIL PROFISSIONAL}

No que tange ao perfil, as profissionais entrevistadas se formaram em períodos diversos que vão de 1984 a 2002. Considerando que o Código de Ética vigente - 1993 -, a Lei de Regulamentação da Profissão de 1993 e as Diretrizes Curriculares de 1996 constituem importantes instrumentos para a defesa de direitos, observa-se que nem todas profissionais tiveram contado com os referidos documentos na graduação. Contudo, não se limitaram ao curso de graduação em Serviço Social, buscando alguma especialização, inclusive na área da saúde. Portanto, todas as entrevistadas possuem uma formação profissional qualificada, permitindo uma intervenção teórica, técnica e ética condizente com as atribuições e competências do assistente social e pautada na perspectiva de garantia de direitos.

Quanto ao tempo de trabalho como assistente social, verifica-se que não ocorre uma prevalência, variando de 15 a 30 anos. Considerando a Unidade Básica de Saúde como espaço sócio-ocupacional, quatro profissionais possuem quatro anos ou mais de inserção nessa instituição. Número esse também referente ao vínculo empregatício de estatutária. Conforme 


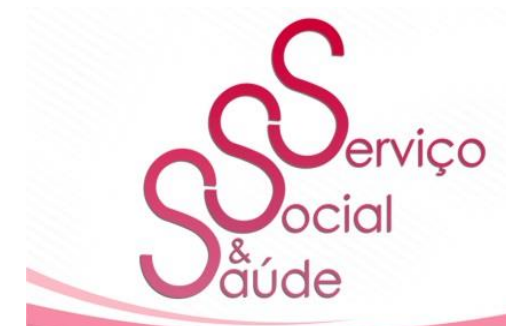

ISSN 2446-5992

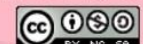

10.20396/sss.v20i00.8665397

aponta Matos (2013), a saúde possui particularidades que precisam ser desveladas pelos profissionais que nela atuam, assim para que os direitos se realizem necessita-se uma relação do projeto ético-político e o da Reforma Sanitária.

No que tange a carga horária observa-se que apesar da Lei 12.317, de 26 de agosto de 2010, que altera o artigo $5^{\circ}$ da Lei de Regulamentação Profissional (Lei 8.662/1993) e define a jornada máxima de trabalho dos assistentes sociais em 30 horas semanais sem redução salarial, todas as profissionais trabalham 40 horas/semanais. Inclusive uma entrevistada relatou que houve uma mobilização coletiva na tentativa de reverter tal situação, porém sem sucesso. Portanto, as próprias trabalhadoras vivenciam uma violação de direito, pois embora reconhecido, formalmente, não se avançou na efetivação da APS do município.

Foi em 2013 que veio a lei, aí nós.... Teve um grupo de profissionais que entrou no nosso sindicato, foi até a nível Federal, mas não conseguimos não (E2).

\section{OBJETIVO DO TRABALHO}

Ao serem questionadas sobre o objetivo de seu trabalho três assistentes sociais apontam ser a questão da garantia, do acesso a direitos. E duas apontam ser os problemas/refrações da questão social. Duas entrevistadas ressaltam que seus trabalhos não se esgotam no âmbito da saúde, inclusive citam como exemplo questões de seguridade social que geram encaminhamentos para a rede socioassistencial. Outra profissional também citou como objetivo a humanização do serviço.

Outra coisa que eu penso é humanizar o serviço, ampliar o acesso do usuário. Eu acho que quando você amplia o acesso você também assegura direito entendeu? (E4)

Ressalta-se que, conforme mencionado anteriormente, a garantia, o acesso a direitos deve se constituir como um meio e não como um fim no trabalho profissional. Constitui-se como uma ferramenta importante para o processo de mobilização, organização e conscientização da classe trabalhadora, mas somente a garantia e o acesso aos direitos não são 


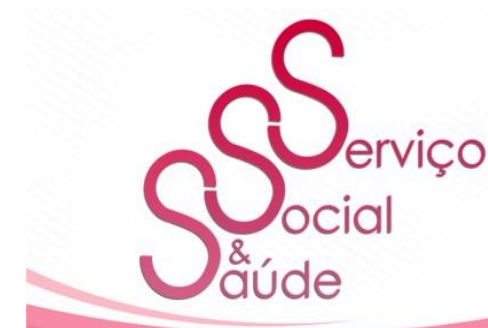

ISSN 2446-5992

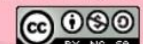

10.20396/sss.v20i00.8665397

capazes de provocar a ruptura na estrutura e na lógica - desigual - do capital.

\section{ATIVIDADES REALIZADAS}

Assim como nas demandas apresentadas, as atividades realizadas são basicamente as mesmas, sendo elas: atendimentos individuais, encaminhamentos, trabalho com grupos, visitas domiciliares, sala de espera, articulação da rede, trabalho com os conselhos. Tal semelhança se explica pelo fato de todas as UBS serem subordinadas à Secretaria Municipal de Saúde, que possui uma normatização da Atenção Primária em Saúde no município. Essa normatização gerou a reorganização dos serviços, buscando uma melhoria na qualidade do referido nível, através da gestão do cuidado e da qualificação do processo de trabalho (humanização, acolhimento, demanda programada por ciclos de vida e com base em riscos e da urgência por grau de risco) e dos profissionais (JUIZ DE FORA, 2016).

Uma entrevistada menciona esse processo como algo positivo para o desenvolvimento de suas atividades, enquanto outra reconhece a importância de uma certa padronização, desde que não interfira na autonomia relativa do profissional.

A prefeitura, através de lei, tem a agenda, que é a agenda desses usuários, do plano diretor. Então eu observo que essa agenda aqui na unidade, e todos os profissionais falando a mesma língua, tem dado certo (E2).

Porém, no que tange ao acolhimento somente uma profissional o cita como uma atividade da sua rotina de trabalho. O que também ocorre com a reunião de equipe e com a supervisão de acadêmicos.

É importante destacar que se observa que as atividades desenvolvidas estão em consonância com os quatro grandes eixos de atuação apontados pelos Parâmetros para atuação de assistentes sociais na política de saúde: atendimento direto aos usuários; mobilização, participação e controle social; investigação, planejamento e gestão; assessoria, qualificação e formação profissional (CFESS, 2010). Assim, as atividades desenvolvidas podem pautar-se na perspectiva de garantir direitos sociais e contribuir para uma melhora nas condições de vida e 


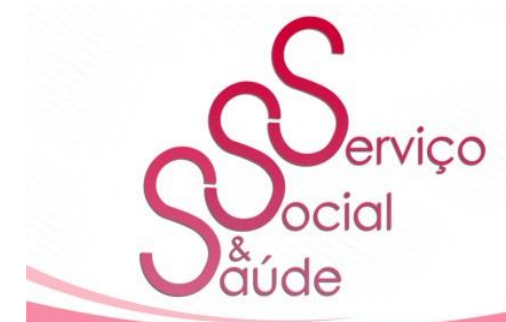

ISSN 2446-5992

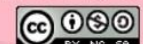

10.20396/sss.v20i00.8665397

de trabalho da classe trabalhadora, ainda que, imediatamente, não altere a estrutura do capitalismo.

Por fim, faz-se necessário uma reflexão: o trabalho desenvolvido pelas assistentes sociais nas UBSs, por vezes demanda que elas realizem atividades de sua competência, mas que não são atribuições privativas do campo do Serviço Social. Desse modo, ao se ocupar, prioritariamente de atividades que não se constituem enquanto atribuições privativas do assistente social, tais profissionais correm o risco de ver dissolvida a sua especificidade, prejudicando e efetivação dos princípios fundamentais da profissão, como por exemplo, a "ampliação e consolidação da cidadania, considerada tarefa primordial de toda sociedade, com vistas à garantia dos direitos civis sociais e políticos das classes trabalhadoras" (CFESS, 1993, p. 23).

\section{A DEFESA DOS DIREITOS}

A defesa de direitos deve se constituir enquanto prioridade da ação profissional do assistente social em qualquer espaço sócio ocupacional, principalmente quando sua inserção ocorre em um ambiente que possui como um dos princípios a universalização do acesso. Pautado em tal perspectiva, o profissional tem condições de se confrontar diretamente com possíveis situações de violação de direitos.

Ao questionar as assistentes sociais sobre a possibilidade de se efetivar uma perspectiva de garantia de direitos em sua atuação, mesmo diante dos limites com os quais se defrontam cotidianamente, inclusive o contexto político atual de desmonte das políticas sociais, todas as entrevistadas afirmam que sim. Assim, toda amostra pesquisada afirma ser possível visualizar a perspectiva da garantia de direitos em sua intervenção profissional. Todas as entrevistadas vinculam a efetivação de tal perspectiva à orientação e/ou informação, inclusive em todas as frentes de trabalho, sejam elas individuais ou coletivas; e duas, mais especificamente, a relacionam diretamente com a questão de cidadania:

Informação, eu acho que a informação é tudo. Quanto mais informado as 


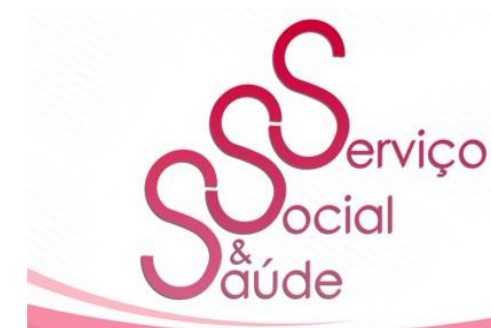

ISSN 2446-5992

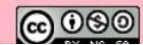

10.20396/sss.v20i00.8665397

pessoas tiverem mais elas vão ter autonomia para tentar resolver as suas questões [...] Você identificar o seu papel enquanto cidadão e aquilo que de fato é seu, seu direito, direito a ter acesso à saúde, à educação, a uma qualidade de vida melhor (E3).

O nosso papel é fundamentalmente orientador, o papel de esclarecer, de informar, de repassar informações, de discutir informações, de destrinchar essas informações para que ele compreenda. E compreenda a importância que ele tem de posse dessas informações fazer com que aquilo que foi garantido em lei seja realmente traduzido pra ele em questão objetiva, prática, cotidiana, rotineira [...] É uma questão de compromisso ético com a profissão [...] O direito dele é nosso também, que também somos cidadãos, também somos povo, então defender as políticas sociais é defender o acesso a essas políticas (E5).

Reforça-se que a possibilidade de proximidade do Código de Ética com o cotidiano profissional, somente se materializa quando o profissional o situa na história da profissão e se apropria de seus valores, fundamentos e finalidades. É necessário entender e utilizar este Código como instrumento profissional tanto para qualificar os serviços prestados, quanto para contribuir na luta pela superação desse modelo de sociedade em que vivemos. Porém, apenas uma profissional faz menção ao referido Código.

Ao indagar se as assistentes sociais identificam violação de direitos dos usuários do SUS na UBS, todas afirmam que identificam e com relativa frequência. Com destaque para violação no que tange a dificuldade de acesso a consultas, principalmente com especialista e em outras políticas. No que tange a reação do Serviço Social, diante de tal contexto de violação, três entrevistadas apontam o controle social como possibilidade (Conselhos, sociedade civil organizada, associação de bairros).

Embora exista uma política nacional no campo da saúde, esta não é suficiente para evitar que direitos sejam violados. Tais violações são questões centrais definidoras dos limites impostos à autonomia profissional. Porém, é possível o estabelecimento de estratégias profissionais e políticas que fortaleçam a defesa dos interesses dos usuários do SUS, trabalhando na garantia de seus direitos, com vistas a tornar o projeto profissional efetivo no cotidiano de trabalho. 


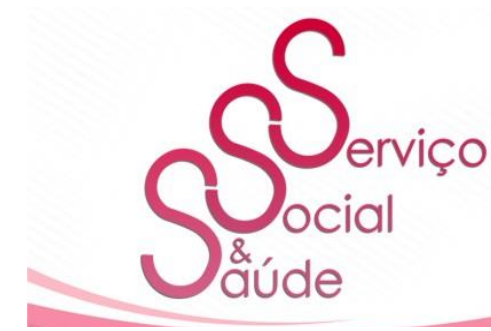

ISSN 2446-5992

(๑)

10.20396/sss.v20i00.8665397

A partir da reflexão sobre as respostas apresentadas pelas profissionais, em vários momentos, surgem características do capitalismo contemporâneo, perpassado pelo ideário neoliberal, o qual estimula a expropriação de direitos, a atrofia do Estado e das políticas sociais.

Desafiadas por um contexto de limites institucionais e estruturais o projeto éticopolítico, então defendido pela categoria profissional, referenda certos valores que norteiam a ação profissional na busca de possibilidades, na medida em que o assistente social possui relativa autonomia na execução de seu trabalho, o que significa oportunidade de imprimir uma direção social às suas ações.

\section{LIMITES E POSSIBILIDADES}

Segue abaixo Tabela 1, com as respostas, sintéticas, das entrevistadas ao serem questionadas sobre os limites que perpassam sua atuação profissional no cotidiano do trabalho.

Tabela 1 - Limites que perpassam a atuação profissional do assistente social

\begin{tabular}{ll}
\hline & \multicolumn{1}{c}{ Limites } \\
\hline Entrevistada 1 & Lugar para atender. \\
Entrevistada 2 & Falta de recursos; falta de concurso público. \\
Entrevistada 3 & Falta de uma rede estruturada. \\
Entrevistada 4 & Falta de articulação, de intersetorialidade das políticas. \\
Entrevistada 5 & Sobrecarga; falta de articulação da equipe e da rede. \\
\hline
\end{tabular}

Fonte: Dados da pesquisa realizada no segundo semestre de 2017.

Constatou-se que todas as assistentes sociais identificam a existência de limites à atuação profissional nas UBS em que atuam. Bem como todas identificam a influência destes limites e desafios nas atividades que desenvolvem.

Percebe-se que os limites estão associados à ausência de investimentos tanto no micro - falta de recursos físicos e materiais para realização de atendimentos, projetos - quanto no serv. soc. \& sauae campinas, sr v. $\angle \mathrm{U}$ \begin{tabular}{l|l|l}
$1-L L$ & eU $\angle I U U 4$
\end{tabular} $\angle \mathrm{U} \angle \mathrm{I}$ e-IDSIN L440-JYYL 


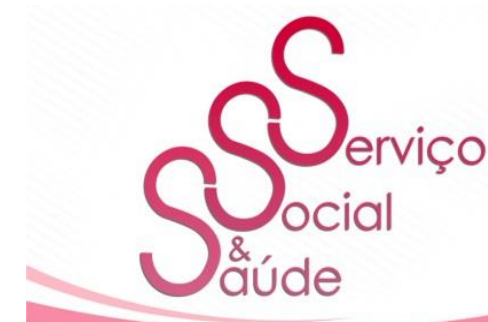

ISSN 2446-5992

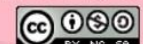

10.20396/sss.v20i00.8665397

macro - uma rede fragmentada e desarticulada. Esta realidade reproduz o descaso do Estado com as políticas sociais, situação agravada pela falta de interesse dos governantes defensores do projeto neoliberal e pela conjuntura socioeconômica das últimas décadas.

Considerando os princípios do SUS, o trabalho em rede, para os assistentes sociais da saúde, se faz primordial, principalmente no que tange a integralidade.

Uma coisa que é do Serviço Social, é intrínseco da nossa profissão, é trabalhar em conjunto, trabalhar coletivo, trabalhar com outros profissionais, sejam eles da saúde ou não. Porque o ser humano ele é integral, ele tem necessidades para poder preencher sua vida, ele pode tá vindo com uma demanda que é uma dor no braço, mas você tem que tá observando, será que essa dor no braço não é efeito de algum trabalho que ele realizou? (E2)

Entretanto, foi perceptível, a partir das falas das profissionais que, apesar da existência de limites e desafios - os quais influenciam no trabalho das assistentes sociais -, vislumbra-se a possibilidade de superá-los através de uma luta diária, de uma ação construída cotidianamente e coletivamente.

O Serviço Social é luta o tempo inteiro, a gente tem que tá realmente disposta a fazer valer aquilo que é direito do usuário (E5).

Todas as entrevistadas citam como possibilidade de atuação, a realização de parcerias, tanto na equipe, quanto na rede ou na comunidade. Também aparecem como possibilidades a escuta e o diálogo com os usuários.

Para tanto, faz-se relevante que o profissional seja capaz de desenvolver um planejamento de suas atividades para propiciar um conhecimento do espaço institucional, do seu histórico, bem como de suas possibilidades e dificuldades. Além, de salvaguardar elementos importantes que subsidiem a análise e intervenções profissionais na realidade.

Identificar possibilidades no cotidiano do trabalho não é uma tarefa fácil, até porque este se coloca como o campo do imediato, do superficial, do pragmático, do fragmentado, das pressões do tempo e da hierarquia. Mas, é neste cotidiano, sob estas pressões, que as assistentes sociais precisam escolher alternativas mais viáveis que permitam o acesso a 


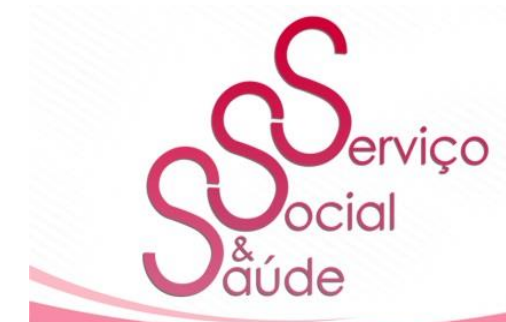

ISSN 2446-5992

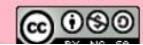

10.20396/sss.v20i00.8665397

direitos. Percebemos que as profissionais acabam, por vezes, se deixando "engolir" por este cotidiano alienante, deixando de participar de espaços de luta coletiva.

$\mathrm{Na}$ tensão entre o impossível e o possível existem possibilidades, desde que os profissionais se proponham a apreendê-las. A estratégia profissional, fundamentada na perspectiva crítico-dialética, deve apontar para a superação das relações sociais fundadas na exploração e na dominação de classe, gênero, etnia. A intervenção sustentada no projeto ético-político e alinhada às lutas sociais enfatiza a democratização, o respeito à diversidade, o compromisso com a qualidade dos serviços prestados, equidade e justiça social, defesa intransigente dos direitos, além da opção de um projeto profissional vinculado ao processo de construção de uma nova sociedade - ultrapassando da emancipação política para emancipação humana.

\section{CONSIDERAÇÕES FINAIS}

Chegando ao final da pesquisa, constatamos que o trabalho do assistente social na Atenção Primária, no município de Juiz de Fora/MG, possui algumas particularidades como: a maioria dos profissionais são contratados de maneira precária, o que gera uma alta rotatividade; não existe substituição de trabalhadores aposentados; os impactos diretos da implementação do Plano Diretor; existem UBSs de formação (como campo de prática de residências), entre outras. E tais particularidades geram outras indagações: a recusa de parte das assistentes sociais em participar do referido estudo teria relação com o tipo de vínculo empregatício? As profissionais contratadas pelo período de um ano conseguem desenvolver o mesmo trabalho que uma profissional efetiva? O trabalho desenvolvido em unidade que recebe residente representa a realidade do município? O Plano Diretor está de fato unificando as ações nas Unidades visando a qualidade ou a quantidade?

Considerando o contexto macrossocietário, também surgem algumas reflexões: é possível garantir uma saúde ampla em um contexto adverso? Até onde a inserção das assistentes sociais em espaços de luta, de construção coletiva de estratégias, poderia ampliar 


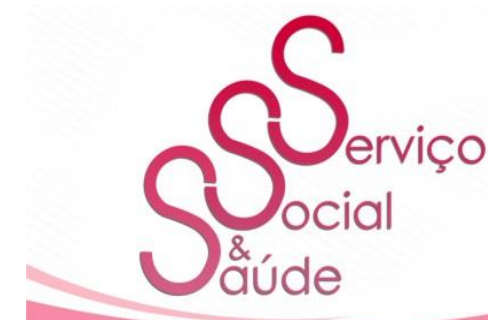

ISSN 2446-5992

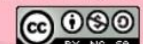

10.20396/sss.v20i00.8665397

sua autonomia profissional? No cotidiano profissional é possível efetivar uma luta pela superação da divisão de classes? O assistente social tem sido chamado para atuar nas omissões geradas pela não efetivação de direitos? A publicização das situações de violação de direitos tornaria estas práticas menos frequentes? Os instrumentos e técnicas profissionais vêm sendo utilizados em uma perspectiva crítico-dialética?

Apesar de todas essas indagações, as reflexões apresentadas nos levam a constatar que, embora exista uma política pública nacional no campo da saúde, a violação dos direitos dos usuários do SUS é uma realidade nas Unidades de Atenção Primária à Saúde, se caracterizando como uma questão complexa. Os assistentes sociais inseridos nessa realidade como em outros espaços sócio-ocupacionais -, encontram limites na sua autonomia profissional, pois pela mesma atividade estão respondendo tanto às demandas do capital quanto do trabalho, podendo fortalecer um ou outro pela mediação do seu oposto (IAMAMOTO, 2008b). É a partir dessa compreensão que se torna possível estabelecer uma estratégia profissional e política que fortaleça os interesses dos usuários do Sistema Único de Saúde, trabalhando na garantia de seus direitos, com vista a construir ações profissionais inspiradas no projeto ético-político, hegemônico no Serviço Social.

Sabemos que identificar possibilidades no exercício profissional não é uma tarefa fácil, diante da realidade que se apresenta no cotidiano do trabalho, mas é nele que as assistentes sociais precisam escolher alternativas mais viáveis, pautadas em uma perspectiva de garantia de direitos. Nesse sentido, a avaliação das atividades pode ser uma ferramenta utilizada visando superar o mero caráter burocrático para buscar a garantia de uma ação competente, propositiva e, quem sabe, capaz de fortalecer a luta por uma outra sociabilidade.

A análise sobre o trabalho dos assistentes sociais inseridos na Atenção Primária à Saúde de Juiz de Fora/MG, não se esgota nesse estudo, sendo possível a problematização de outras questões que aparecem como respostas, o que possibilitará novas interpretações e contribuições para o trabalho realizado por estas profissionais. Em outras palavras, não é propósito esgotar a temática ou oferecer respostas acabadas aos questionamentos apontados. Isso porque, na perspectiva desse estudo a realidade é vista de forma contraditória, em 


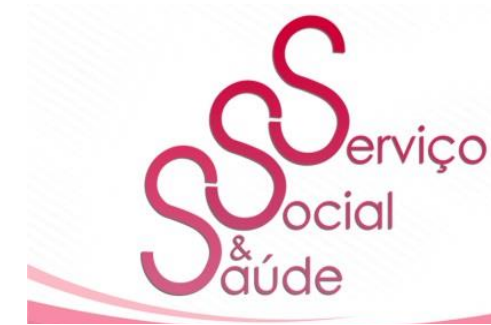

ISSN 2446-5992

(c) (1) (3)

10.20396/sss.v20i00.8665397

processo passível de mudanças de acordo com as ações dos sujeitos sócio-históricos e políticos que nela estão inseridos.

\section{REFERÊNCIAS}

BRASIL. Constituição da República Federativa do Brasil. Brasília: Senado Federal, 1988.

BRASIL. Política Nacional de Atenção Básica. Brasília: Ministério da Saúde, 2012.

Disponível em: < http://189.28.128.100/dab/docs/publicacoes/geral/pnab.pdf >. Acessado em 25 de novembro de 2017.

BUSSINGER, V. V. Fundamentos dos Direitos Humanos. Serv. Soc. Soc. Ano XVIII, n. 53. São Paulo: Cortez, 1997.

CASTRO, M. M. de C. Trabalho em saúde: a inserção do assistente social na atenção primária à saúde em Juiz de Fora/MG - orientadora: Lêda Maria Leal de Oliveira. Juiz de Fora: UFJF, Faculdade de Serviço Social, 2009 (Dissertação de mestrado).

CFESS. Código de ética profissional do assistente social. Brasília, 1993.

CFESS. Parâmetros para atuação de assistentes sociais na política de saúde. Brasília, 2010.

COUTINHO, C. N. Contra a corrente: ensaios sobre democracia e socialismo. São Paulo: Cortez, 2008.

FAGNANI, E. O fim do breve ciclo da cidadania social no Brasil (1988-2015). Texto para discussão. Campinas: Unicamp. IE, no 308, 2017. Disponível em: < file:///C:/Users/Karola/Downloads/TD308\%20(1).pdf >. Acessado em 05 de junho de 2018. IAMAMOTO, M. V.; CARVALHO, R. Relações Sociais e Serviço Social no Brasil: esboço de uma interpretação histórico-metodológica. São Paulo: Cortez, 2008.

IAMAMOTO, M. V. O Serviço Social na Contemporaneidade: trabalho e formação profissional. São Paulo: Cortez, 2008. (a)

IAMAMOTO, M. V. O Serviço Social em Tempo de Capital Fetiche: Capital financeiro, trabalho e questão social. São Paulo: Cortez, 2008. (b) 


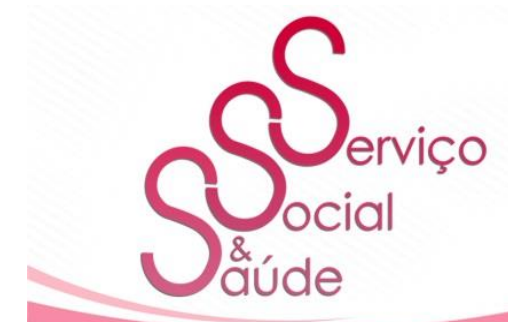

ISSN 2446-5992

(c) 10 (2)

10.20396/sss.v20i00.8665397

JUIZ DE FORA. Catálogo de Normas da Atenção Primária à Saúde. Juiz de Fora: Funalfa, 2016.

MASCARO, A. L. A crítica do Estado e do direito: a forma política e a forma jurídica. Curso livre Marx-Engels. São Paulo: Boitempo, Carta Maior, 2015.

MATOS, M. C. Serviço Social, Ética e Saúde - Reflexões Para o Exercício Profissional. São Paulo: Cortez, 2013.

MENDES, E. V. As redes de atenção à saúde. Ciência e saúde coletiva, v. 15, nº 5 . Rio de Janeiro: 2010.

MIOTO, R. C. T.; NOGUEIRA, V. M. R. Sistematização, planejamento e avaliação das ações dos assistentes sociais no campo da saúde. Serviço Social e Saúde: Formação e Trabalho Profissional. São Paulo: Cortez, 2008.

NETTO, J. P. Transformações societárias e Serviço Social: notas para uma análise prospectiva da profissão no Brasil. Serv. Soc. Soc. Ano XVII, n. 50. São Paulo: Cortez, 1996 NETTO, J. P.; BRAS, M. Economia Política: uma introdução crítica. São Paulo: Cortez, 2006.

SILVA, M. M. V. A. Capitalismo e políticas sociais: o dilema da autonomia dos cidadãos e da defesa da universalidade dos direitos sociais. Estado e Cidadania: Reflexões sobre as políticas públicas no Brasil contemporâneo. Rio de Janeiro: FVG, 2012.

TRINDADE, J. D. L. Os direitos humanos na perspectiva de Marx e Engels: Emancipação política e emancipação humana. São Paulo: Alfa-Omega, 2011.

VASCONCELOS, A. M. de. A prática do Serviço Social: cotidiano, formação e alternativas na área da saúde. São Paulo: Cortez, 2011. 